\title{
Analysis and Countermeasures of Wenzhou under The Belt and Road
}

\author{
Yue Chen ${ }^{1, \text { a }}$, Zhanao Wang ${ }^{2,3, \text { b, * }}$ \\ ${ }^{1}$ School of foreign languages and international trade, Wenzhou Business College, Zhejiang 325035, \\ China; \\ ${ }^{2}$ School of public affairs, Zhejiang University, Zhejiang 325035, China; \\ ${ }^{3}$ School of foreign languages and international trade, Wenzhou Business College, Zhejiang 325035, \\ China; \\ a18758710108@163.com, ${ }^{b}$ wzawhu@163.com
}

Keywords: Belt and Road; economy; construction

Abstract: In 2013, when General Secretary Xi Jinping visited Central Asia and Southeast Asia, he proposed to build the economic belt of the Silk Road and the 21st Century Silk Road. The Silk Road Economic Belt is the longest economic belt in the world. It is the economic corridor with the most economic development potential. The construction of the Silk Road Economic Belt is an important support for deepening the new round of development in the eastern coastal areas. It is not only a key strategy of the country, but also a strategy to further deepen the opening up of the eastern coastal areas. In the process of re-planning the international value chain of enthusiastic enterprises, there is a very important platform to give play to the advantages of promoting the development of the foreign economic zone. Therefore, from the background of the "Belt and Road", this paper explores the opportunities and countermeasures for the development of open economy in Wenzhou, and further improves the level of economic development and construction in Wenzhou. A strong national economy has important practical significance. On the other hand, the practice of Wenzhou City can also provide important guiding significance for the development of open economy in other cities along the eastern coast.

\section{Introduction}

"In 2013, when General Secretary Xi Jinping visited Central Asia and Southeast Asia, he proposed to build the economic belt of the Silk Road and the 21st Century Silk Road.” The Silk Road Economic Belt is the longest economic belt in the world. It is the economic corridor with the most economic development potential. The construction of the Silk Road Economic Belt is an important support for deepening the new round of development in the eastern coastal areas. It is not only a key strategy of the country, but also a strategy to further deepen the opening up of the eastern coast. "The most important part of the entire economic belt is the eastern coastal region and the Central Asian countries," said Sheng Yi, deputy director of the Wenzhou Academy of Social Sciences. The strength of the impact and the principle of the barrel are suspected. If the weak link is 
underdeveloped, it will be difficult to form the entire economy. band. Therefore, for China, the highest priority for current construction is the eastern coastal region. But the point from the eastern coastal area of Wenzhou is considered to be an well-equipped and important supporting role to play the economic belt. It is the economically and densely populated province of Wenzhou, because it is an important aviation hub and railway. Therefore, Wenzhou City should seize the opportunity provided by the "Belt and Road" to promote economic development in the eastern coastal areas and actively promote the development of an open economy. The "Belt and Road" initiative provides a rare opportunity for Wenzhou enterprises to develop.

Although Wenzhou City is not listed as a "Belt and Road" city, it has a unique advantage that cannot be ignored - Wenzhou resources. Wenshang is the leader of the "Belt and Road" strategy. At present, 380,000 people in Wenzhou work in 57 countries and regions along the "Belt and Road". In the process of re-planning the international value chain, enthusiastic enterprises have a very important platform to play an advantage in promoting the development of the foreign economic zone. At present, there are 20 Wenzhou domestic and foreign trade and economic cooperation regions in the country, and the area outside the national park is the largest city-level county. The Wenzhou Trade Statistics Bureau showed that in 2016, the "Belt and Road" and the state-related bilateral trade in Wenzhou reached more than 40 billion yuan, while agricultural trade accounted for only $2.12 \%$ of this, indicating that not only in agricultural trade issues, Wenzhou also showed The huge potential, due to the resonance effect of the Wenzhou Yangtze River and the two regional economic circles, means that the high-end elements of resource flows will become the core of the city, which is a disadvantage. Wenzhou needs to avoid weaknesses and take the initiative of the “One Belt, One Road” initiative from the Wenzhou model. Agriculture and rural development should be worthy of attention during this time, Wenzhou as a commercial agriculture and coastal city, including the company's business activities and agricultural aspects, including fisheries and agroforestry, so analyze the current situation and integration issues in Wenzhou It is necessary to build a "Belt and Road" to explore scientific countermeasures.

\begin{tabular}{|c|c|c|c|c|c|c|c|}
\hline \multicolumn{2}{|c|}{} & \multicolumn{9}{|c|}{ The Belt and Road breakdown of regional exports } \\
\cline { 2 - 8 } Years & Total export & $\begin{array}{c}5 \\
\text { countries } \\
\text { in Central } \\
\text { Asia }\end{array}$ & $\begin{array}{c}16 \\
\text { countries } \\
\text { on the } \\
\text { land }\end{array}$ & $\begin{array}{c}\text { 19 countries } \\
\text { in Europe }\end{array}$ & $\begin{array}{c}6 \\
\text { countries } \\
\text { in South } \\
\text { Asia at } \\
\text { sea }\end{array}$ & $\begin{array}{c}\text { All the } \\
\text { way to } \\
\text { the } \\
\text { northeast } \\
\text { of the } 6 \\
\text { countries }\end{array}$ & $\begin{array}{c}\text { Southeast } \\
\text { Asian } \\
\text { countries } \\
\text { all the way } \\
\text { to the sea } \\
11\end{array}$ \\
\hline 2013 & 166621.00 & 2131.93 & 9049.58 & 23190.22 & 2991.93 & 214.06 & 1756.07 \\
\hline 2014 & 185705.00 & 3138.89 & 7232.15 & 23937.05 & 3111.34 & 112.09 & 1092.60 \\
\hline 2015 & 155296.00 & 2474.15 & 5136.39 & 15460.51 & 4071.77 & 88.74 & 840.29 \\
\hline 2016 & 146426.70 & 4258.24 & 5256.05 & 17502.47 & 3461.06 & 102.55 & 688.06 \\
\hline 2017 & 146940.62 & 2425.47 & 4633.26 & 23691.92 & 3936.61 & 37.63 & 614.85 \\
\hline $\begin{array}{c}\text { average } \\
\text { value }\end{array}$ & 160197.86 & 2885.74 & 6261.49 & 20756.43 & 3514.54 & 111.01 & 998.37 \\
\hline
\end{tabular}

From a practical point of view, on the one hand, Wenzhou City further improves the opening of the door to the outside world, the level of the eastern coastal areas of Wenzhou City, the location advantage is not clear, in the special period of "new economic normal", will be Wenzhou City 2020 To achieve zero poverty in the year, it is very difficult and important to build a well-off society in an all-round way. Therefore, this paper combines the background of "One Belt, One Road" to explore the opportunities and countermeasures of Wenzhou's open economy development, which has important practical significance for Wenzhou to further improve its economic development level and build a strong national economy. On the other hand, the smooth development of Wenzhou 
City can also provide important guiding significance for the development of open economy in other cities along the eastern coast.

\section{Wenzhou City's main investment strategy involving "the Belt and Road"}

\subsection{Local companies lack competitiveness}

Since most of the countries along the "Belt and Road" belong to developing countries, there are huge differences in politics, culture, law, religious beliefs, and economic development levels. Therefore, in the process of "going out", Wenzhou enterprises need to face the policy system environment and social customs of different countries and regions, and also face the ever-changing market supervision system, facing anti-monopoly, intellectual property protection, and taxation. Multiple legal risks such as labor, environment, etc. However, due to the lack of in-depth understanding of the above information, some enterprises have the desire to invest abroad, but they are unable to implement the corresponding plans, or encounter unnecessary troubles and losses in the implementation of foreign investment. At present, the enterprises going abroad are mainly engaged in overseas new investment. At present, Wenzhou has established three national-level and one provincial-level overseas economic and trade cooperation zones along the "Belt and Road", becoming the prefecture-level city with the largest number of national-level overseas parks in the country. However, the overall operation is not mature, and the local economy is not obvious. Among the existing enterprises in Wenzhou, there is a lack of internationally renowned brands, and the proportion of private brands is relatively small. Most of them are mainly branded and OEM. The high-end links in various industries are generally underdeveloped. Most of them are in the international division of labor and the global industrial chain. In the middle and low-end links, the products are mostly low-end products with low technical content, low added value and weak market competitiveness. Most products are at the low end of the industrial chain and value chain. Enterprises rely mainly on low-cost, low-price competition, low industrial level, scattered layout, and weak competitiveness.

\subsection{Investment stability is gradually enhanced}

From the perspective of export and foreign investment, although Wenzhou's participation in the "Belt and Road" process is not high, it has received many miraculous effects in terms of foreign investment. Animal products in Wenzhou's countries along the Belt and Road Initiative include pet food and aquatic animals. In recent years, Wenzhou "Belt and Road", which exports to the region along the line, encourages food to carry out the "One Belt, One Road" initiative, and has formed a relatively stable market, and exports have shown a recovery growth, improving the overall small size, but due to the decline of its raw materials, international leader The price of finished products fell, and the value of exports did not change significantly. With the export of aquatic animals "along the way" caused by the national economic growth boom in 2014 and 2015, the market demand for exports has remained significant due to the sharp decline in export leading enterprises due to poor business management in 2016. Among the factories and plant products exported to Wenzhou along the "Belt and Road" countries, bamboo products, grass and vegetable seeds rank first. In recent years, the overall value has changed slightly, with a slight decline, mainly due to the weakness of the national economy and the sluggish external demand. Export foods include aquatic products, vegetable products, rice flour, food additives, etc. As well as the export of various commodities along the "Belt and Road", the process continues to rise. The large number of commodities exported by Wenzhou City have brought more recognized development opportunities for the development of “One Belt, One Road”. 


\section{Analysis of the Advantages and Disadvantages of Open Economy Development under the Background of "One Belt, One Road" in Wenzhou}

\subsection{Advantages}

Wenzhou has a long history of openness, but also because of its rich resources. With the development of the economy, the means of transportation have evolved. In recent years, it has gained a lot of political support from the country. These are favorable internal factors for the development of an open economy in Wenzhou.

No policy development can be separated from national and local policies. In 2000, China announced the implementation of the national development strategy of the eastern coastal provinces of Zhejiang, seized the opportunity to become a major eastern coastal economic sanction, grasped the economic foundation, and Wenzhou exited "comprehensive reforms and promoted reforms in certain system regions. And determined that a comprehensive test plan will be used in the Zhejiang region as a comprehensive reform experiment. In January 2016, Hangzhou, Wenzhou and other countries became the national commercial pilot; in August 2016, the country established a new round for Wenzhou. Free trade zone. The development of these open platform policies is another advantage of Wenzhou's development of an open economy. For example, the rise and progress of the "One Belt, One Road" in the apparel industry cannot be separated from the support of the policy.

From the data in the table, since the "Belt and Road", the number of countries and regions involved in the apparel industry has increased, and the amount of economic possession involved has also increased. It is not difficult to see that not only the clothing industry is like this. Under the policy, all kinds of industries are also continually drawing on their interests.

\subsection{Disadvantages}

Since Wenzhou involved the "Belt and Road", it mainly traded with countries along the way. According to official statistics, in January 2017, the total foreign trade volume was more than 120 billion yuan, but the total foreign investment was only $\$ 450$ million, of which investment accounted for $68.9 \%$ along the "Belt and Road" of \$310 million, despite the "Belt and Road". "The total amount of foreign investment is a large proportion of investment in China Overseas, but the trade volume in Wenzhou is different in front of different regions of the same country. Despite the economic and trade construction, Wenzhou is in the forefront of the country to meet the rapid performance of international capabilities. For example, the Qingshan Iron and Steel Project in Indonesia is smelting iron and nickel alloys. It is the largest overseas production company in Wenzhou. It is an overseas project of Wenzhou Tianxiang Ocean. Fisheries Malaysia Development Co., Ltd. cooperates with Malaysian Xingfa Group registered fishery to jointly develop the Malaysian Water Fish Marine Construction Project Processing Park. However, compared with the province, Hangzhou and Ningbo have shaped the development status of "One Belt, One Road". Wenzhou Company uses cross-border mergers and acquisitions and strives to acquire advanced foreign technology, high-end talents.

\section{Acknowledgement}

This paper was supported by Study on private enterprises participating in Wenzhou Social Science Planning Projects (Wenzhou participates in the current situation, problems and countermeasures of "The Belt and Road"), Wenzhou Social Science Planning Projects (Research on Carrier Function, Agglomeration Effects and Improvement Approach of Wenzhou Overseas 
Economic and Trade Cooperation Zones, project no.18wsk229) and China Postdoctoral Science Foundation (Studies on the Evolution Rules and Policies of the Asia-pacific Multilateral FTA from the Perspective of Relative Gains, project no.2017M611965)

\section{References}

[1] Cheng Enfu. Economic Globalization and China's Countermeasures [M]. Shanghai: Science and Technology Literature Publishing House, 2000.

[2] Zhong Shan. Analysis of Open Economy Research [M]. Beijing: China Business Press, 2003.

[3] Zhao Wei. International trade theory policy and practical issues [M]. Dalian: Dongbei University of Finance and Economics Press, 2004.

[4] Mu Liuwei. International Investment and Financing Theory and Practice [M]. Chengdu: Southwestern University of Finance and Economics Press, 2004.

[5] Feng Yue, Xia Hui. International trade theory, policy and case analysis [M]. Beijing: Peking University Press, 2012.

[6] Wang Guimin. Multidimensional Interpretation of Open Economy: Theoretical Foundation and Practical Operation [M]. Beijing: China Social Sciences Press, 2014.

[7] Xu Wei. The "Belt and Road” Opportunities and Challenges of China's Foreign Trade [J]. China Foreign Capital, 2017(1).

[8] Zhang Jianhua. Development prospects, business opportunities and challenges of the "One Belt, One Road" strategy [J]. Business Economics Research,2015 (35).

[9] Liu Hui, Ye Erken, Wu Zhati, etc. The influence of the "Belt and Road" occupation on the open space pattern of China's land [J]Progress in Geography, 2015 (3).

[10] Zhao Tianrui, Sun Chengwu, etc. The opportunities and challenges of regional economic development under the "One Belt, One Road” strategic background [J]. Economic Issues, 2015(12).

[11] Liao Dongsheng, Long Liting. Research on the Development of Open Economy in Guangxi under the Background of “One Belt, One Road” Strategy[J]. Reform and Strategy, 2017(1).

[12] Zhang Yumei. Sichuan Province: Exploring the establishment of a service trade system into the assessment [N]. International Business Daily, 2015-5-11.

[13] Zeng Qing. The difficult reversal on the road of foreign trade [N]. Sichuan Daily, 2017-2-7.

[14] Zeng Xiaoqing, Gu Qiang. Nearly 3,000 foreign trade Sichuan enterprises were added in July before the "10,000 enterprises went abroad” [N]. Sichuan Daily, 2016-8-23. 